www.jmscr.igmpublication.org

Impact Factor 5.244

Index Copernicus Value: 5.88

ISSN (e)-2347-176x ISSN (p) 2455-0450

crossref DOI: _http://dx.doi.org/10.18535/jmscr/v4i4.51

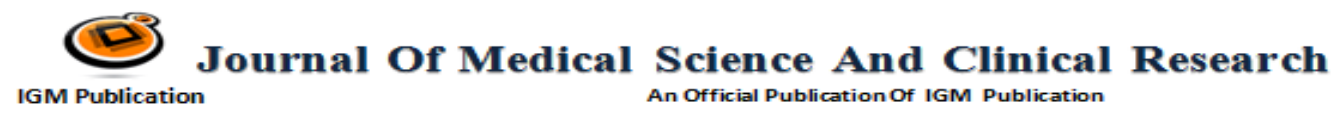

An official Publication of IGM Publication

\title{
HIV and Tuberculosis: the impact goes beyond those infected with HIV/AIDS \\ (Original Article)
}

\author{
Authors \\ Sanjay Kumar Garg ${ }^{1}$, Shivraj Meena ${ }^{2}$, Shivcharan jelia ${ }^{3}$, S.R Meena ${ }^{4}$ \\ ${ }^{1}$ Medical officer, Department of Medicine, NMCH, Govt Medical College Kota, Rajasthan, India \\ ${ }^{2}$ Assistant Professor, Department of Medicine, NMCH, Govt Medical College Kota, Rajasthan, India \\ ${ }^{3}$ Professor, Department of Medicine, NMCH, Govt Medical College Kota, Rajasthan, India \\ ${ }^{4}$ Senior Professor, Department of Medicine, NMCH, Govt Medical College Kota, Rajasthan, India \\ Corresponding Author \\ Dr Sanjay Kumar Garg
}

House no. 6, Suman Vihar, Bundi Road, Kunhari, Kota Rajasthan, India Pincode-324008

Email-doctorsanjaygarg@yahoo.com, Mobile - +919414331357

\begin{abstract}
Background \& objectives: Tuberculosis is said to be one of the commonest opportunistic infection in patients with HIV/ AIDS. In this study the clinical profile of tuberculosis in patient with HIV infection /AIDS and to study the pulmonary and extra pulmonary tuberculosis involvement and clinical profile in HIV infection/AIDS subjects.

Methods: HIV sero-positive patients with symptoms suggestive of pulmonary and extra pulmonary tuberculosis, attending the Outpatient Departments and indoor at Department of Medicine, Govt. Medical College, Kota.

Results: fever (97.1\%), weight loss (85.7\%) cough (80\%), pallor (68.5\%) mouth ulcer (41.4\%) and lymphadenopathy (33\%). Incidence of both Pulmonary and extra pulmonary tuberculosis were almost same (45.71\%).Among extra pulmonary tuberculosis, abdominal TB was (18.57\%). Infiltrative lesions were $(54.28 \%)$ on chest $x$-ray. Sputum positivity was seen only in $31.25 \%$ of patients. Mean CD4 counts was $133.95+141.89$ cells/ $\mu \mathrm{l}$. Most of the patients $(78.57 \%)$ had CD4 counts $<200$ cells $/ \mu l .77 \%$ of sputum negative TB, $88.32 \%$ of extra pulmonary TB had CD4 cell count $<200$ cells/ $\mu$ l. and $100 \%$ of disseminated TB had CD4 cell count $<50$ cells/ $\mu l .90 \%$ Sputum positive cases were seen with CD4 cell count $>50$ cells/ $\mu \mathrm{l}$.

Conclusion- most common manifestation of TB in HIV infected patients were sputum negative pulmonary TB. A high proportion of cases with extra pulmonary TB were also found. There is an urgent need to strengthen the information, education and expand the ART services to meet the requirement of early testing and treatment initiation in patients co-infected with HIV-TB.

Keywards- HIV/TB, AIDS, Tuberculosis, Extrapulmonary TB.
\end{abstract}

\section{Introduction}

Co-infection of Human Immunodeficiency Virus (HIV) and tuberculosis (TB) is considered to be one of the emerging medical conditions responsible for huge social and economic burden globally. Tuberculosis is a leading cause of 
mortality among people living with HIV/AIDS. Tuberculosis infection with HIV weakens the immune system and activates latent tuberculosis infection ${ }^{1}$.

In countries with high prevalence of TB as well as HIV, tuberculosis is a very common presentation of AIDS and, in most cases, it is the earliest manifestation. Clinical and surveillance data show that in Asia, TB is the most important lifethreatening opportunistic disease associated with HIV, For example, in Thailand, 60\% of AIDS patients seen in a Bangkok hospital between 1985 and 1991 had pulmonary tuberculosis 25 and TB is the most common reported cause of hospitalization and death among AIDS patients in Thailand. Surveillance data from India and Nepal show that $83 \%$ and $56 \%$ of AIDS patients had tuberculosis. ${ }^{2}$

The World Health Organization (WHO) estimated 8.8 million incident cases of TB globally in 2010; with 12-14 per cent of cases among people with $\mathrm{HIV}^{3}$. India accounted for maximum number of incident cases of TB (2-2.5 million) worldwide, with an estimated 5.0 per cent (3.3-7.1\%) having HIV co-infection ${ }^{3}$. Despite the high burden of disease, there is a paucity of data from India on response to anti-tuberculosis treatment (ATT) in patients with HIV-TB co-infection ${ }^{4-6}$. Information on the pattern of TB, the outcome of ATT and the associated factors will help in planning interventions to improve outcomes in this patients. ${ }^{15}$

In India, human immunodeficiency virus (HIV) testing is performed as a voluntary test or as a diagnostic procedure in symptomatic individuals ${ }^{7}$. HIV testing is a part of screening procedure in antenatal clinics as a mode of prevention of parent to child transmission (PPTCT). It is also done in all tuberculosis (TB) patients due to the strong association between HIV and $\mathrm{TB}^{8}$. In spite of these various HIV testing opportunities, earlier a majority of infected individuals became aware of their status only after they developed opportunistic infections in the late stages ${ }^{9,10}$.
In present study was carried out to assess the clinical symptoms and signs of TB (Pulmonary Tuberculosis and Extra-pulmonary Tuberculosis) are differ from non-HIV infected patients. There are few studies of clinical profile of Tuberculosis in HIV infected patients. Present work was designed to study the clinical profile (signs, symptoms, laboratory investigations), comparison of various studies of HIV infected and make a proper clinical diagnosis.

\section{Material \& Methods}

HIV sero-positive patients with symptoms suggestive of pulmonary and extra pulmonary tuberculosis attending the Outpatient Departments and indoor at Department of Medicine, Govt. Medical College, Kota from may 2012 to April 2014. Total seventy patients were selected randomly in this study. This is a type of prospective study.

A written informed consent was taken from each patients included in the study after thorough counseling. All cases were selected, taking into consideration the inclusion \& exclusion criteria. Inclusion criteria were Subject having HIV serology positive by ELISA test. Patients having pulmonary involvement with sputum positive acid fast bacilli and/ or supported by MT test. Patients were having extra pulmonary involvement with positive acid fast bacilli other than sputum viz. lymph node, CSF, Pleural fluid, ascitic fluid. Extra pulmonary involvement with negative acid fast bacilli but other tubercular marker positive (ADA, TB PCR) and/ or supported by MT test. Exclusion criteria were any antecedent history of hypertension, diabetes mellitus, heart disease, chronic renal disease and Ischemic heart disease. If they were fulfilled the inclusion criteria. The patients had to be more than 15 year old male and female. A detailed history including previous antituberculosis therapy, addictions \& high-risk sexual behavior was elicited. A general clinical examination was performed. Baseline investigations such as chest X-ray, two sputum specimens for AFB smear, culture and drug 
sensitivity and blood examination were performed as detailed below. All the positive cultures were subjected to drug susceptibility tests using standard methods. HIV screening was performed using the Tridot Rapid Test; all positive results were confirmed using Comb Aids Rapid test and also by ELISA. Hemoglobin, total and differential leukocyte cell counts, blood sugar, blood urea, serum creatinine, serum uric acid and liver function tests were performed and ultrasound abdomen. The CD4, CD8 cell counts and CD4/CD8 ratio were determined using flow cytometry (Simultest-lMK Lymphocyte kit).Tuberculin skin (Mantoux) test,Lymph nodes, FNAC and biopsy, Pleural and ascitic fluid analysis and TB PCR.CECT chest \& abdomen was done in needy patients. All infected TB/HIV patients were send to DOTS center for anti tubercular treatment in respected category.

Statistical analysis was performed with the statistical package for the social science system version SPSS 17. Continuous variables are presented as mean $\pm \mathrm{SD}$, and categorical variables are presented as absolute numbers and percentage.

\section{Results}

In this study, seventy HIV positive patients with Tuberculosis were studied, of this 54 were males and 16 were females. In this study maximum number of patients were in 30-39 years age group in which 25 were Male and 8 were females (Table 1) The mean age was $36.44 \pm 9.70$ (37.2 \pm 9.75 for males and $33.87 \pm 9.42$ for females).Common occupation among the study group was drivers (28.5\%), followed by Laborers \& housewives (20\%), farmers (11.5\%), Shopkeepers/ businessmen's (10\%), govt. servant (7.15\%), others $(2.85 \%)$ (Table 2$)$.

In this study, common constitutional symptoms reported were fever (97.1\%), weight loss $(85.7 \%)$. Common respiratory symptoms reported were $\operatorname{cough}(80 \%)$, breathlessness $(65.7 \%)$ and chest discomfort (45.7\%).Common gastrointestinal symptoms reported were anorexia (32\%), abdominal distention (18.5\%) and altered sensorium $8.57 \%$. Physical examination revealed that pallor in $68.5 \%$, icterus in $12.8 \%$, lymphadenopathy in $10 \%$ and mouth ulcer in $41.4 \%$ (Table 3)

In 70 HIV patients $32(45.71 \%)$ had only pulmonary $\mathrm{TB}$ and only extra pulmonary $\mathrm{TB}$ in $32(45.7 \%)$ in which abdominal TB was seen in $13(18.57 \%)$, tubercular pleural effusion in $10(14.28 \%)$, tubercular lymphadenopathy in $6(8.57 \%) \&$ TB meningitis in 3(4.28\%) and disseminated TB in 6(8.57\%) (Table 4)

Out of 35 patients with abnormal X-rays infiltrative lesions were seen in 19(54.28\%), fibrocavitory lesions seen in $11(34.11 \%)$ and miliary mottling $5(14.28 \%$ ) (Table 5).In this study CD4 >200 cells was seen in 15(21.5\%), 50-200 cells in $32(45.7 \%)$ and $<50$ in $23(32.8 \%)$ of patients. The mean CD4 count in this study was133.95 141.89 ,mean CD4 among males was $121.57 \pm 126.60$ and females was $175.75 \pm 183.22$ (table 6)

In this study sputum negative PTB was seen in $27.27 \%$ of $<50$ CD4 counts patients, $50 \%$ of 50 200 cells CD4 counts patients and $22.72 \%$ of $>200$ cells CD4 counts patients. Sputum positive PTB was seen in $10 \%$ of $<50$ CD 4 counts patients, $40 \%$ of $50-200 \mathrm{CD} 4$ counts patients and $50 \%$ of $>200$ CD4 counts patients. Disseminated TB was seen in $100 \%$ ( all) of <50 CD4 counts patients. EPTB was present in $31.21 \%$ of $<50$ CD4 counts patients, $53.12 \%$ of $50-200 \mathrm{CD} 4$ counts patients and $15.6 \%$ of $>200 \mathrm{CD} 4$ counts patients. Thus $77 \%$ of sputum negative pulmonary $\mathrm{TB}$ and $88.32 \%$ of extra pulmonary TB was seen in CD4 $<200$ cells counts patients (Table 7) 
Table 1: Demographic characteristics of the study participants

\begin{tabular}{|c|c|c|c|c|c|c|c|}
\hline \multirow{2}{*}{$\begin{array}{l}\text { Age } \\
\text { (Years) }\end{array}$} & \multirow[t]{2}{*}{ Group } & \multicolumn{2}{|c|}{ Male } & \multicolumn{2}{|c|}{ Female } & \multicolumn{2}{|c|}{ Total } \\
\hline & & No & $\%$ & No & $\%$ & No & $\%$ \\
\hline$<21$ & & 3 & 5.5 & 1 & 6.2 & 4 & 5.7 \\
\hline $21-29$ & & 8 & 14.8 & 2 & 12.5 & 10 & 14.3 \\
\hline $30-39$ & & 25 & 46.3 & 8 & 50 & 33 & 47.1 \\
\hline $40-49$ & & 10 & 18.5 & 4 & 25 & 14 & 20 \\
\hline $50-59$ & & 6 & 11.1 & 1 & 6.2 & 7 & 10 \\
\hline $60+$ & & 2 & 3.8 & 0 & 0 & 2 & 2.9 \\
\hline Total & & 54 & 100 & 16 & 100 & 70 & 100 \\
\hline
\end{tabular}

Table 2: Distribution of study population by occupation

\begin{tabular}{|l|l|l|}
\hline Occupation & No. of patients & Percentage \\
\hline Farmer & 8 & $11.5 \%$ \\
\hline Driver & 20 & $28.5 \%$ \\
\hline Labour & 14 & $20 \%$ \\
\hline Shopkeeper/ Business man & 7 & $10 \%$ \\
\hline House wife & 14 & $20 \%$ \\
\hline Government Servant & 5 & $7.15 \%$ \\
\hline Others & 2 & $2.85 \%$ \\
\hline Total & 70 & $100 \%$ \\
\hline
\end{tabular}

Table 3: Distribution of symptoms \& signs in study population

\begin{tabular}{|l|l|l|}
\hline Symptoms & No. of patients & Percentage \\
\hline Fever & 68 & $97.1 \%$ \\
\hline Weight Loss & 60 & $85.7 \%$ \\
\hline Cough & 56 & $80 \%$ \\
\hline Shortness of Breathing & & $65.7 \%$ \\
\hline Chest discomfort & 32 & $45.7 \%$ \\
\hline Altered Sensorium & 6 & $8.57 \%$ \\
\hline Abdominal Distension & 13 & $18.5 \%$ \\
\hline Anorexia & 23 & $32 \%$ \\
\hline Signs & & \\
\hline Mouth Ulcer & 29 & $41.1 \%$ \\
\hline Pallor & 48 & $68.5 \%$ \\
\hline Icterus & 9 & $12.8 \%$ \\
\hline Lymphadenopathy & 7 & $10 \%$ \\
\hline
\end{tabular}


Table 4: Distribution by Clinical Manifestation of Tuberculosis

\begin{tabular}{|l|l|l|}
\hline & No. of Patients & Percentage \\
\hline Pulmonary Tuberculosis & 32 & $45.71 \%$ \\
\hline Extrapulmonary tuberculosis & 32 & $45.71 \%$ \\
\hline - Tubercular Lymphadenopathy & 6 & $8.57 \%$ \\
\hline - Tubercular Meningitis & 3 & $4.28 \%$ \\
\hline - Abdominal tuberculosis & 13 & $18.57 \%$ \\
\hline -Tubercular Pleural Effusion & 10 & $14.28 \%$ \\
\hline Disseminated tuberculosis & 6 & $8.57 \%$ \\
\hline Total & 70 & $100 \%$ \\
\hline
\end{tabular}

Table 5: Distribution according to Chest X-ray Findings

\begin{tabular}{|l|l|l|}
\hline Chest X-ray Findings & No. of patients & Percentage \\
\hline Infiltrative & 19 & $54.28 \%$ \\
\hline Fibro cavitatory & 11 & $31.4 \%$ \\
\hline Miliary mottling & 5 & $14.28 \%$ \\
\hline
\end{tabular}

Table 6: Distribution of study population according to CD4 Counts

\begin{tabular}{|l|l|l|}
\hline CD4 Counts (cells) & No. of patients & Percentage \\
\hline$>200$ & 15 & $21.5 \%$ \\
\hline $50-200$ & 32 & $45.7 \%$ \\
\hline$<50$ & 23 & $32.8 \%$ \\
\hline
\end{tabular}

Table 7: Relation between CD4 Range and Clinical manifestations of TB

\begin{tabular}{|l|l|l|l|l|l|}
\hline CD4 Count & $\begin{array}{l}\text { Sputum } \\
\text { Negative } \\
\text { PTB }\end{array}$ & $\begin{array}{l}\text { Sputum } \\
\text { Positive } \\
\text { PTB }\end{array}$ & $\begin{array}{l}\text { Disseminated } \\
\text { TB }\end{array}$ & EPTB & Total \\
\hline$<50$ & $6(27.27 \%)$ & $1(10 \%)$ & $6(100 \%)$ & $\begin{array}{l}10 \\
(31.21 \%)\end{array}$ & $23(32.85 \%)$ \\
\hline $50-200$ & $11(50 \%)$ & $4(40 \%)$ & $0(0 \%)$ & $\begin{array}{l}17 \\
(53.12 \%)\end{array}$ & $32(45.7 \%)$ \\
\hline$>200$ & $5(22.72 \%)$ & $5(50 \%)$ & $0(0 \%)$ & $5(15.6 \%)$ & $15(21.5 \%)$ \\
\hline Total & $22(100 \%)$ & $10(100 \%)$ & $6(100 \%)$ & $32(100 \%)$ & $70(100 \%)$ \\
\hline
\end{tabular}




\section{Discussion}

Present study carried out in 70 patients at Government Medical College and Associated Group of Hospitals, Kota.

In our study, out of 70 patients, $77 \%$ of patients were males and $22.9 \%$ females. Other study done by Deivanayagam $\mathrm{CN}$ et al ${ }^{11}$ in which $79.25 \%$ were males and rest $20.75 \%$ were females. $\mathrm{NACO}^{7}$ National Statistics also show s similar distribution of subjects of which $74 \%$ were males and $26 \%$ females. This observation is similar to study by Zuber Ahmad et al ${ }^{12}$ where $84.6 \%$ were males and $15.4 \%$ were females.

In our study most of the people $(47.1 \%)$ were in the 30-39 age groups, with mean age of males being 37.2 years and mean age of females 33.85 years. This is comparable to the study done by Deivanayagam $\mathrm{CN}$ et $\mathrm{al}^{11}$ in which $74.94 \%$ of patients belonged to 21-40 years; Praveen Kumar et $\mathrm{al}^{13}$ observed $69 \%$ of patients belonged to $21-40$ years. National Statistics reported to $\mathrm{NACO}^{7}$ shows $89 \%$ of cases were in the age group of 15 44 years. This age reflects the sexually active age group which is commonly affected by the disease In our study group most common occupation were unskilled drivers (28.5\%), laborers (20\%), and farmers $(11.5 \%)$, which indicate the co-infection affected people of low socio-economic status. Praveen Kumar et $\mathrm{al}^{13}$ found a similar occupation profile with $38 \%$ manual laborers, $21.4 \%$ driver, $11.9 \%$ drivers and $19 \%$ other while in study done by Anand K.Patel et al $^{14} 30 \%$ were farmer $16 \%$ driver and $22 \%$ were manual laborers by occupation. so we can conclude that economical status of study groups were similar. We can conclude that tuberculosis is generally occurring in low socioeconomic population because of poor hygiene and diet and over crowed living condition.

In our study commonest presenting symptoms were fever $97.1 \%$ followed by weight loss $85.9 \%$, cough $80 \%$, breathlessness $65.7 \%$ and anorexia $32 \%$.in study conducted by Anand K Patel et al ${ }^{14}$ most common symptoms was fever $86 \%$ respectively, while in study by Deivanayagam et $\mathrm{al}^{11}$ and Zuber Ahmed et al ${ }^{12}$ cough was the commonest symptoms $85.43 \%$ and $97 \%$ respectively because in these studies pulmonary TB was more than extra pulmonary TB. Weight loss was the second most common presenting symptoms in our study (85.7\%). Zuber Ahmed et $\mathrm{al}^{12}$ and Anand $\mathrm{K}$ Patel et $\mathrm{al}^{14}$ also observed weight loss in $97 \%$ and $78 \%$ patients respectively where as Deivanayagam et $\mathrm{al}^{11}$ observed weight loss in $49.69 \%$.

In our study Sputum positive for AFB in HIV patients with pulmonary TB and disseminated TB was present in $28.57 \%$. Zuber Ahmed et $\mathrm{al}^{12}$ observed $36.54 \%$ of Sputum positive cases. It is probably because in our study number of fibrocavitory lesions were $31.4 \%$ and in Zuber Ahmed et al $^{12}$ fibrocavitory lesions were $42.69 \%$. In other studies Praveen kumar et $\mathrm{al}^{13}$ and Anand K. Patel et al ${ }^{14}$ observed $21.4 \%$ and $25.58 \%$ of patients with in Sputum positivity respectively.

In our study in X-rays chest, infitrative lesions were seen in 19(54.28\%), fibrocavitory lesions seen in $11(34.11 \%)$ and miliary mottling $5(14.28 \%)$. X-rays chest findings was observed in study conducted by Zuber Ahmed et $\mathrm{al}^{12}$ observed infiltrative lesions in $65(62.5 \%)$, fibrocavitory lesions in 34(32.69\%) and miliary mottling in 5 $(4.81 \%)$.

In our study patients with pulmonary tuberculosis and extra pulmonary tuberculosis were almost equal $32(45.71 \%)$, which is same as in studies of Anand $\mathrm{K}$ patel et $\mathrm{al}^{14}$ observed pulmonary tuberculosis in $61.54 \%$ patients. It is probably because; these studies have larger number of patients. We also observed disseminated TB in $8.57 \%$ of patients which is same as Anand $\mathrm{K}$ patel et $\mathrm{al}^{14}$.

In our study among Extra pulmonary TB, Abdominal TB was seen in $18.57 \%$, Tubercular Pleural effusion in $14.2 \%$, Tubercular lymphadenopathy in $8.57 \%$, and Tuberculosis meningitis in $4.28 \%$. Similar Extra pulmonary TB was observed in study conducted by Praveen kumar et $\mathrm{al}^{13}$ observed Abdominal TB 14.8\%, Tubercular Pleural effusion 9.5\%, Tubercular 
lymphadenopathy $11.9 \%$, and Tuberculosis meningitis $7.2 \%$. Anand $\mathrm{K}$ patel et $\mathrm{al}^{14}$ observed Abdominal TB 12\%, Tubercular Pleural effusion $6 \%$, Tubercular lymphadenopathy 20\%, and Tuberculosis meningitis in $8 \%$ of cases.

\section{Conclusion}

In this study, most common manifestation of TB in HIV infected patients were sputum negative pulmonary TB. A high proportion of cases with extra pulmonary TB were also found. There is an urgent need to strengthen the information, education and expand the ART services to meet the requirement of early testing and treatment initiation in patients co-infected with HIV-TB.

\section{Acknowledgements}

Authors are thankful to medical and nursing staff of the medicine ward for their cooperation in the study.

Funding: No funding sources

Conflict of interest: None declared

Ethical approval: The study was approved by the institutional ethics committee.

\section{References}

1. Girardi, E., Goletti, D., Antonucci, G., \& Ippolito, G. (2001). Tuberculosis and HIV: A deadly interaction. J Biol Regul Homeost Agents, 15(3), 218-23.

2. Harries AD and Maher D. TBIHIV - A Clinical Manual World Health Organization Publication (Geneva) WHO/TB/96.200.

3. World Health Organization. 5. Global tuberculosis control: WHO report. 2011. Geneva: WHO; 2011. p. 9-27.

4. Vijay 6. S, Kumar P, Chauhan LS, Rao SV, Vaidyanathan P. Treatment outcome and mortality at one and half year followup of HIV infected TB patients under TB control programme in a district of South India. PLoS One 2011; 6 : e21008.
5. Swaminathan7. S, Deivanayagam $\mathrm{CN}$, Rajasekaran S, Venkatesan P, Padmapriyadarsini C, Menon PA, et al. Long term follow up of HIV-infected patients with tuberculosis treated with 6month intermittent short course chemotherapy. Natl Med J India 2008; 21: 3-8.

6. Tripathy S8., Anand A, Inamdar V, Manoj $\mathrm{MM}$, Khillare KM, Datye AS, et al. Clinical response of newly diagnosed HIV seropositive \& seronegative pulmonary tuberculosis patients with the RNTCP Short Course regimen in Pune, India. Indian J Med Res 2011; 133: 521-8.

7. National AIDS Control Organization (NACO). Department of AIDS Control, Ministry of Health and Family Welfare, Government of India, New Delhi, Annual Report 2010-11. New Delhi: NACO; 2011.

8. National AIDS Control Organization and Central TB Division.2. National Framework for Joint HIV/TB Collaborative Activities. October 2009. New Delhi: National AIDS Control Organization and Central TB Division, Ministry of Health and Family Welfare, Government of India; 2009. p. 12.

9. Wortley PM, Chu SY, Diaz T, Ward JW, Doyle B, Davidson 3. AJ, et al. HIV testing patterns: where, why, and when were persons with AIDS tested for HIV? AIDS 1995; 9 : 487-92.

10. Kumarasamy N, Solomon S, Chaguturu SK, Cecelia AJ, 4. Vallabhaneni S, Flanigan TP, et al. The changing natural history of HIV disease: Before and after the introduction of generic antiretroviral therapy in Southern India. J Clin Infect Dis 2005; 41: 1525-8.

11. C.N. Deivanayagam, S. Rajasekaran, V.Senthilnathan, O.R. Krishnarajasekhar, K. Raja, C. Chandrasekar, S. Palanisamy, A. Samuel Dinesh, G. Jothivel and S. V. Elango Clinico-radiological spectrum of 
tuberculosis among HIV sero-positives - a

Tambaram study .Ind. J Tub., 2001,48, 123.

12. Zuber Ahmad, Rakesh Bhargava, D.K Pandey and K. Sharma HIV infection seroprevalence in tuberculosis patients Ind.J.Tub.,2003,50,151

13. Praveen Kumar, Niraj Sharma, N.C. Sharma. Clinical Profile of Tuberculosis in Patients with HIV Infection/AIDS. Indian J Chest Dis Allied Sci 2002; 44: 159-163

14. Anand K. patel, sandip j. thakrar, feroz d. ghanchi. Study on clinical and laboratory profile of patients with TH/HIV coinfection: a case series of 50 patients.lung india 2011:28;93-6.

15. Surendra K. Sharma, Manish Soneja, K.T. Prasad \& Sanjay Ranjan. Clinical profile $\&$ predictors of poor outcome of adult HIV-tuberculosis patients in a tertiary care centre in north India. Indian $\mathrm{J}$ Med Res 139, January 2014, pp 154-160 